\title{
A comparison of cell-culture plasticwares for effective human cytokine-induced killer cell culture
}

\author{
Panwadee Pluangnooch, Chaiphichit Phayangkhe, Kitipong Soontrapa
}

\begin{abstract}
Background: Cytokine-induced killer (CIK) cells are ex-vivo expanded T cells which present a phenotype of both T and Natural Killer cell properties.
\end{abstract}

Objective: To compare the proliferation and functional properties of human CIK cells cultured in three cell culture plasticwares.

Methods: The number and viability of CIK cells were monitored. The expression of surface markers (CD3 and CD56), TH1 cytokines (IFN- $\gamma$ and TNF- $\alpha$ ), and cytolytic granules (granzyme B and perforin) were determined by flow cytometry.

Results: The number of CIK cells cultured in a static bag was highest compared to those in a petri dish and gas-permeable flask. However, CIK cells cultured in all plasticwares similarity expressed surface marker, TH1 cytokines, and cytolytic granules.

Conclusion: Considering safety, efficacy, and cost, a static bag is the best plasticware for culturing CIK cells.

Key words: cytokine-induced killer cells, cell culture plasticware, static bag, gas-permeable flask, immunotherapy

\section{From:}

Department of Pharmacology, Faculty of Medicine Siriraj Hospital, Mahidol University, Bangkok, Thailand

\section{Corresponding author:}

Kitipong Soontrapa

Department of Pharmacology

Faculty of Medicine Siriraj Hospital, Mahidol University

2 Wanglang Road, Bangkoknoi, Bangkok 10700, Thailand

E-mail: kitipong.soo@mahidol.ac.th

\section{Introduction}

Cytokine-Induced Killer (CIK) cells, which are ex-vivo expanded $\mathrm{T}$ cells exhibiting the phenotypic and functional characteristics of both cytotoxic $\mathrm{T}$ and natural killer (NK) cells, are generated by culturing peripheral blood mononuclear cells (PBMC) in the presence of interferon gamma (IFN- $\gamma$ ), monoclonal antibody against CD3 (anti-CD3), and interleukin-2 (IL-2) for a few weeks. ${ }^{1-3}$ CIK cells can kill cancer cells, due to their high production of cytotoxic mediators, including interferon-gamma (IFN- $\gamma)$, tumor necrosis factor-alpha (TNF- $\alpha$ ), granzyme B, and perforin in a non-major histocompatibility complex (MHC)-restricted manner. ${ }^{1,4,5}$

CIK cell-based immunotherapy has been clinically determined to be safe and effective in treating many hematologic and solid cancers. ${ }^{6-8}$ Besides cancer treatment, CIK cells can be applied to alleviate allergic airway inflammation, as has been shown in an animal study. ${ }^{9}$ Due to the several therapeutic benefits of CIK cells, it is crucial to develop an effective method to obtain a large number of CIK cells. In the process of culturing CIK cells, the selection of cell culture plasticware is essential.

In our study, we compared three cell culture plasticwares: a petri dish, static bag, and gas-permeable flask, in culturing human CIK cells by monitoring the cell number, viability, surface marker, and the production of cytokines and cytotoxic granules.

\section{Methods \\ Subjects}

Blood samples were collected from healthy donors $(n=8)$ after informed consent. All experimental protocols were approved by the Siriraj Institutional Review Board (SIRB), Faculty of Medicine, Siriraj Hospital, Mahidol University, Bangkok, Thailand (COA no. Si 606/2018). 


\section{Generation of CIK cells}

Peripheral blood mononuclear cells (PBMC) were isolated by standard Isoprep (Robbins Scientific, CA) centrifugation of whole blood. An adhesion period of one hour was performed in a petri dish. A non-adherent cells population was harvested and subsequently plated in a petri dish (Corning, USA), a static bag (NIPRO, Japan), and a gas-permeable flask (G-rex, US) in equal volume at a concentration of $4 \times 10^{6}$ cells $/ \mathrm{mL}$ in RPMI-1640 medium (Gibco, USA), supplemented with 10\% fetal bovine serum (Biochrom, Germany), $100 \mathrm{U} / \mathrm{mL}$ penicillin and $100 \mu \mathrm{g} / \mathrm{mL}$ streptomycin (Gibco, USA), and $1000 \mathrm{U} /$ $\mathrm{mL}$ recombinant human IFN- $\gamma$ (ImmunoTools, Germany) at $37^{\circ} \mathrm{C}$ in a $5 \% \mathrm{CO}_{2}$ incubator. Twenty-four hours later, the cultures were stimulated with $50 \mathrm{ng} / \mathrm{mL}$ anti-human CD3 MAb (BioLegend, CA) and $300 \mathrm{U} / \mathrm{mL}$ recombinant human IL-2 (Miltenyi Biotec, Germany). The culture was maintained by the addition of a fresh medium with $300 \mathrm{U} / \mathrm{mL}$ IL-2 every three to four days. On day 14, the CIK cells were collected and counted (Figure 1).

\section{Detection of immunophenotype by flow cytometry}

For cell-surface proteins, FITC-conjugated anti-human CD3 (ImmunoTools, Germany) and APC-conjugated anti-human CD56 (ImmunoTools, Germany) were used. For intracellular cytokines (IFN- $\gamma$ and TNF- $\alpha$ ) and cytolytic granules (granzyme B and perforin)-staining, PBMC and CIK cells were stimulated for four hours at $37^{\circ} \mathrm{C}$ in a $5 \% \mathrm{CO}_{2}$ with 50 $\mathrm{ng} / \mathrm{mL}$ phorbol 12-myristate 13-acetate (PMA) (Sigma-Aldrich, USA), and $1 \mu \mathrm{g} / \mathrm{mL}$ ionomycin (Sigma-Aldrich, USA) in the presence of a GolgiPlug ${ }^{\mathrm{mm}}$ Protein Transport Inhibitor (BD Biosciences, USA). The cells were fixed and permeabilized with BD Cytofix/Cytoperm according to the manufacturer's instructions, and were stained with PE-conjugated anti-human IFN- $\gamma$ (ImmunoTools, Germany) or granzyme B (Miltenyi Biotec, Germany) and APC- conjugated anti-human TNF- $\alpha$ or perforin (BioLegend, CA). Alternatively, propidium iodide (PI) (Miltenyi Biotec, Germany) uptake was used to detect cell death. Data acquisition was performed using a CytoFLEX flow cytometer (Beckman coulter, US), and analysis was done using CytExpert (Beckman coulter, US).

\section{Statistical analysis}

The results are shown as the mean \pm standard error of the mean (SEM). Data were analyzed using the GraphPad Prism 5 statistics program. One-way ANOVA with Tukey's Multiple Comparison Test was used to analyze the statistical significance of the difference between means for the four experimental groups, and $p<0.05$ was considered statistically significant.

\section{Results \\ Assessment of CIK cells expansion}

Three cell culture plasticwares were compared for their effectiveness in culturing CIK cells (Figure 2). CIK cells cultured in a static bag yielded the highest total cell numbers $(2610.00 \pm 588.77)$, compared to those in a petri dish and a gas-permeable flask (1421.25 $\pm 481.61,1926.88 \pm 397.42$, respectively) (Figure 3A). Regarding viability, CIK cells cultured in a gas-permeable flask showed a significant decrease in the percent of cell death, as compared to the CIK cells from a petri dish. However, there was no significant difference in the percentage of dead cells between those cultured in a petri dish and a static bag (Figure 3B).

\section{The phenotypes of CIK cell}

The cellular composition of PBMC and CIK cells that expanded in a petri dish, static bag, or gas-permeable flask was determined by a flow cytometer. CD3 and CD56 surface markers specific to CIK cells were examined (Figure 4). The numbers of $\mathrm{CD}^{+}{ }^{+} \mathrm{CD} 56^{+}$cells from the $\mathrm{CIK}$ cells cultured in all the cell-culture plasticwares were comparable. Regarding the functional evaluation of the CIK cells, the production of TH1 cytokines (IFN- $\gamma$ and TNF- $\alpha$ ) was measured using flow cytometry. The CIK cells highly expressed the cytokines and cytolytic granules, granzyme $\mathrm{B}$, and perforin. However, all the cell culture plasticwares yielded relatively similar results (Figure 5).

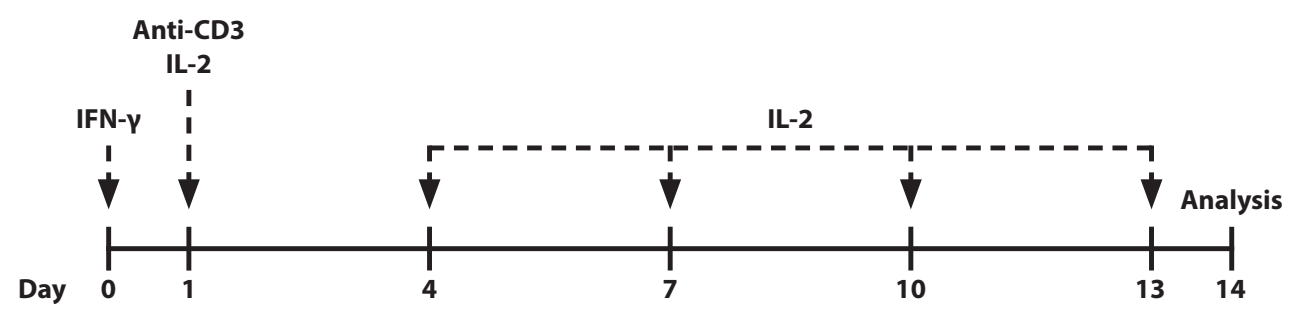

Figure 1. A diagram of the protocol for generating CIK cells.

PBMC maintained at a density of $4 \times 10^{6}$ cells $/ \mathrm{ml}$ were stimulated with $1000 \mathrm{IU} / \mathrm{ml} \mathrm{IFN}-\gamma$ for $24 \mathrm{~h}$. Next, cells were stimulated with $50 \mathrm{ng} / \mathrm{ml}$ anti-CD3 $\mathrm{mAb}$, and $300 \mathrm{IU} / \mathrm{ml} \mathrm{IL-2.} \mathrm{The} \mathrm{culture} \mathrm{was} \mathrm{supplemented} \mathrm{with} 300 \mathrm{IU} / \mathrm{ml} \mathrm{IL}-2$ at an interval of two to three days. After 14 days, the cells were analyzed. 


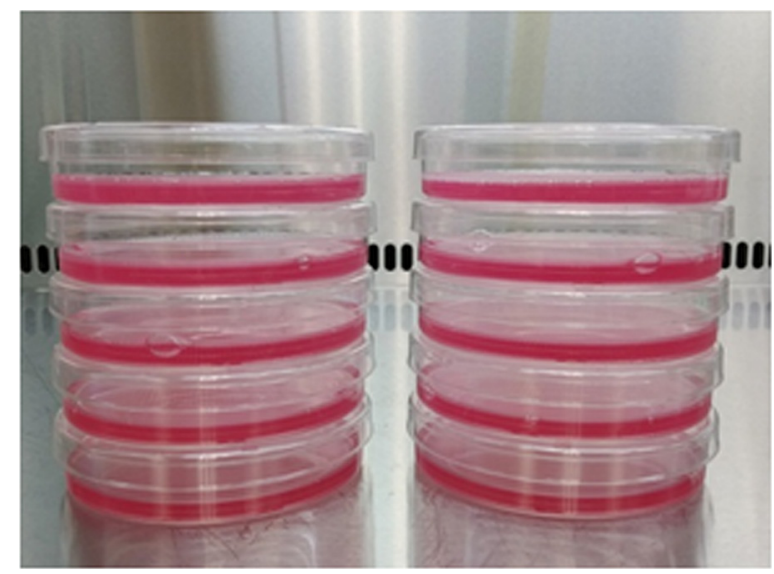

Petri dish

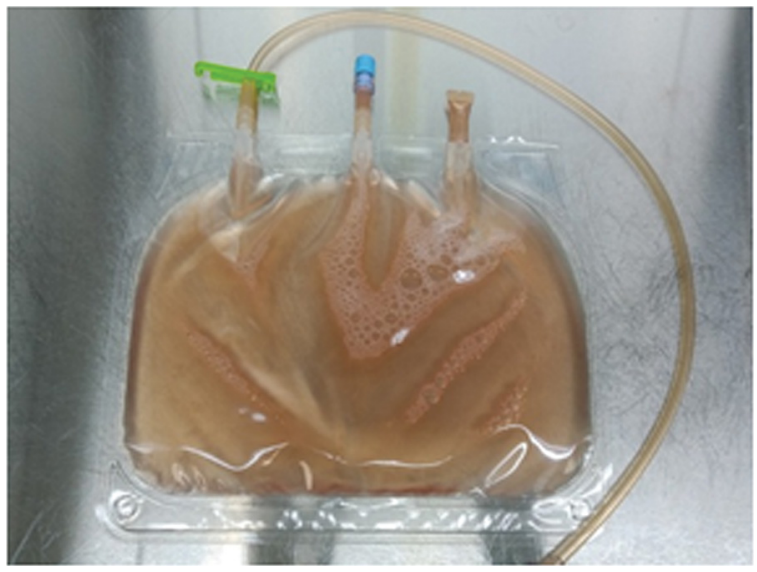

Static bag

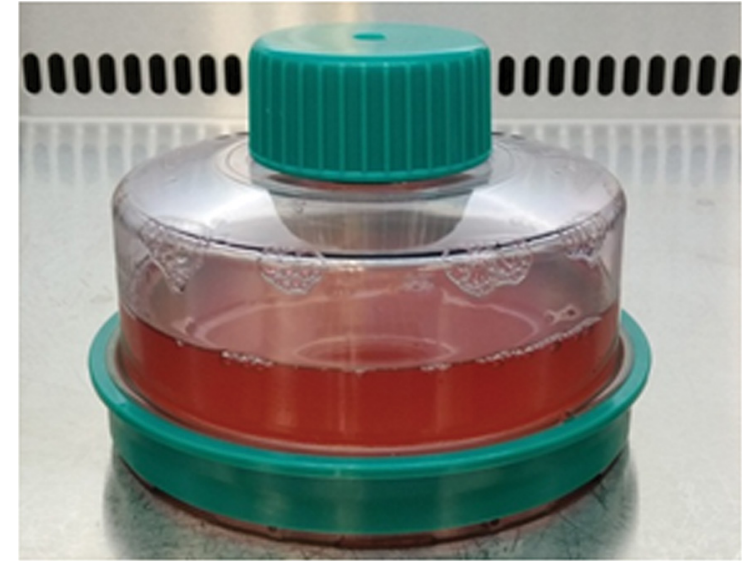

Gas-permeable flask

Figure 2. CIK cells-culture plasticwares

The panel shows schematic diagrams of a petri dish, static bag, and gas-permeable flask, respectively.

A

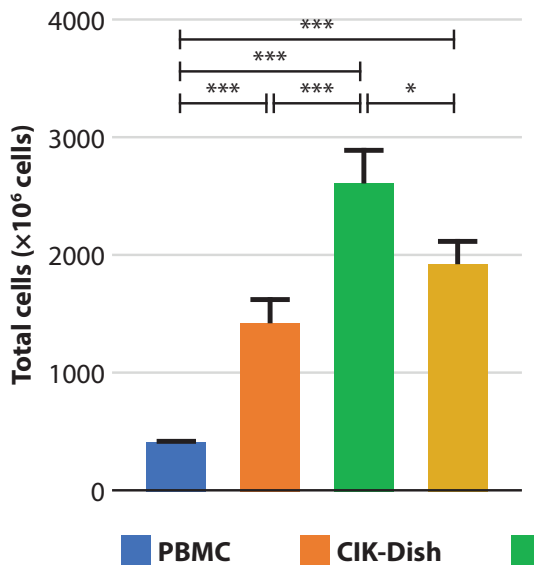

B
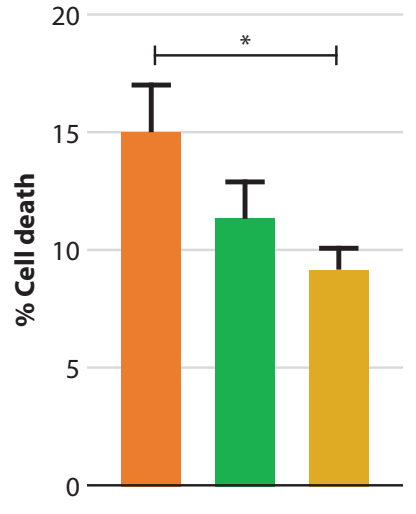

CIK-Bag

CIK-Flask

Figure 3. Quantification of CIK cells

This shows the total cell numbers of PBMC, CIK cell culture using a petri dish, static bag, and gas-permeable flask on day 14 (A). The percentage of dead cells was quantified after propidium-iodide staining by a flow cytometer (B). The data shown are the mean absolute number of cells \pm SEM from three separate experiments $\left({ }^{\star}, p<0.05 ;{ }^{* *}, p<0.005 ;{ }^{* *}, p<0.001\right)$. 

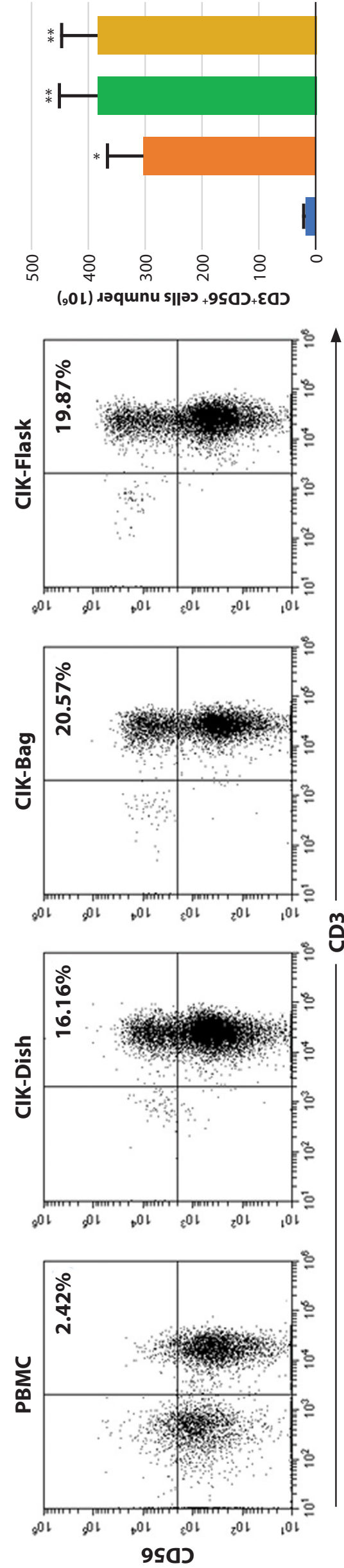
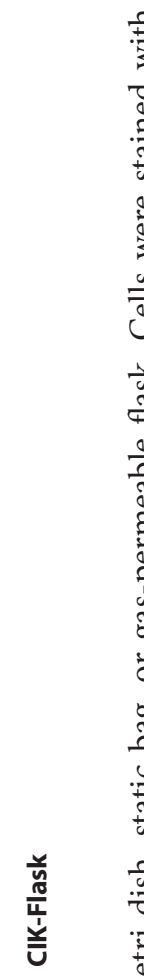

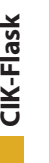

我

牙

苛,

$\pi$ 品

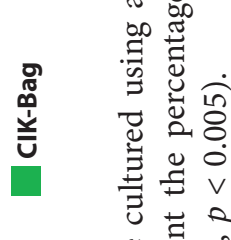

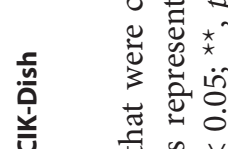

$\exists$ D $v$

$\nexists \stackrel{2}{2} \stackrel{0}{2}$

ô

$\sum_{\substack{0 \\ 0}}^{u}$

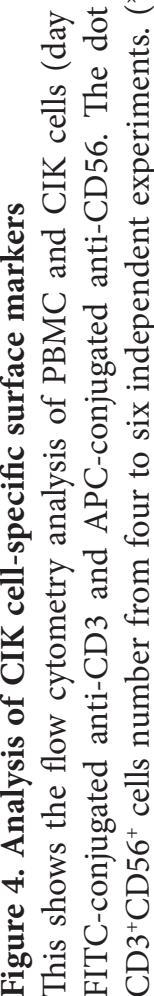

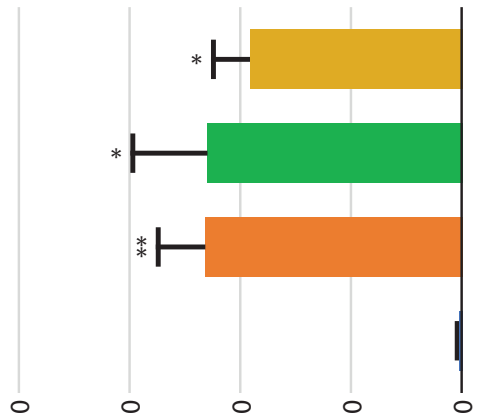

ঃ \& \& \&

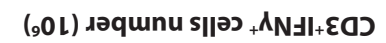
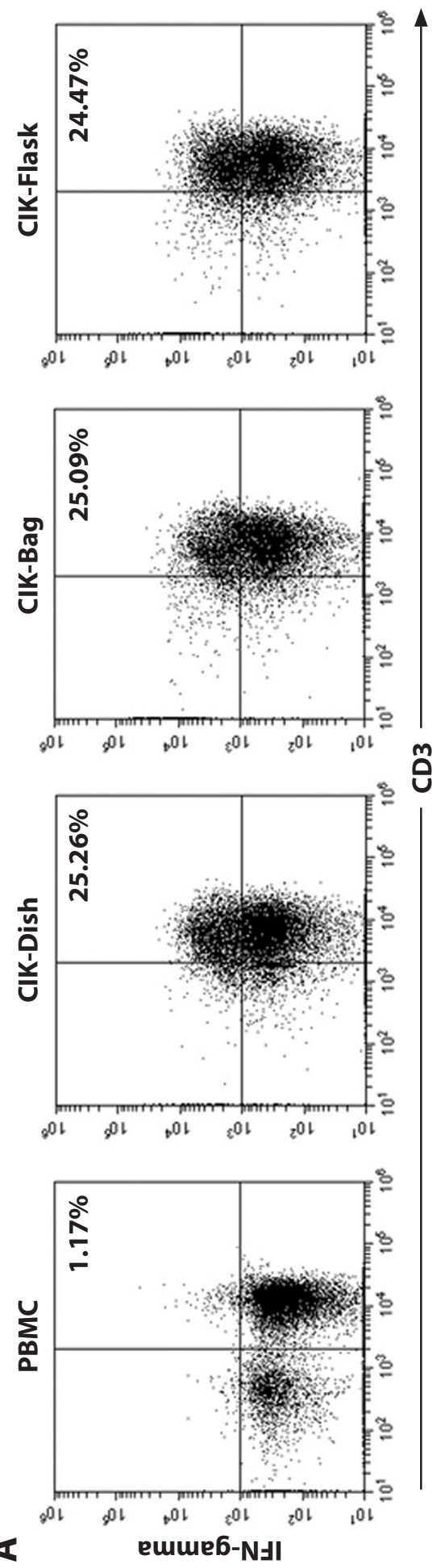

䇋苛宽

S。

定

密 莺

产 के

के

营苛苛

象㟧

F

跑

ते क्ष

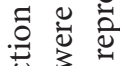

峞

चี

造部

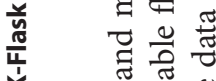

氜 Е

$\ddot{ \pm} \dot{0}$

䆛

ฐึ छ ठै

ป. $\Xi$ ติ

ठै.

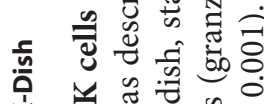

姜

प.

0 क

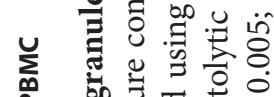

o

西节的

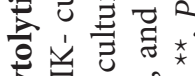

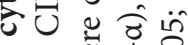

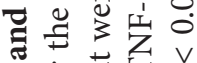

它焉

表吉交太

总它宁

可要苋

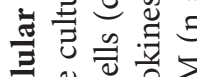

过 눙

光光的

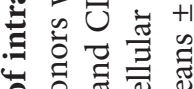

응 훠

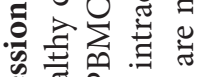

㻤

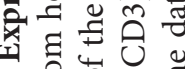

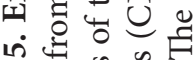

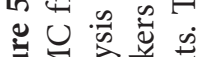

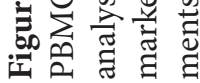




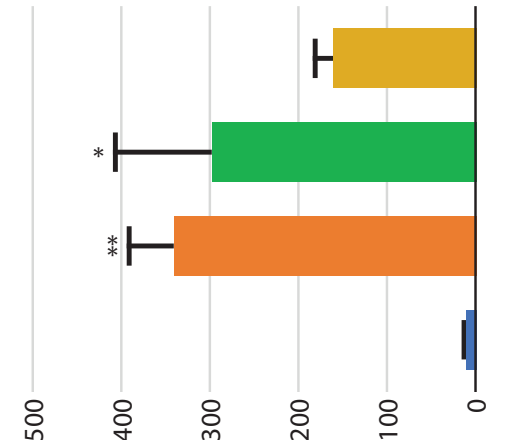

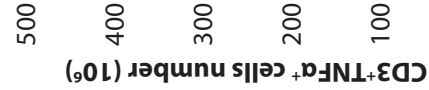
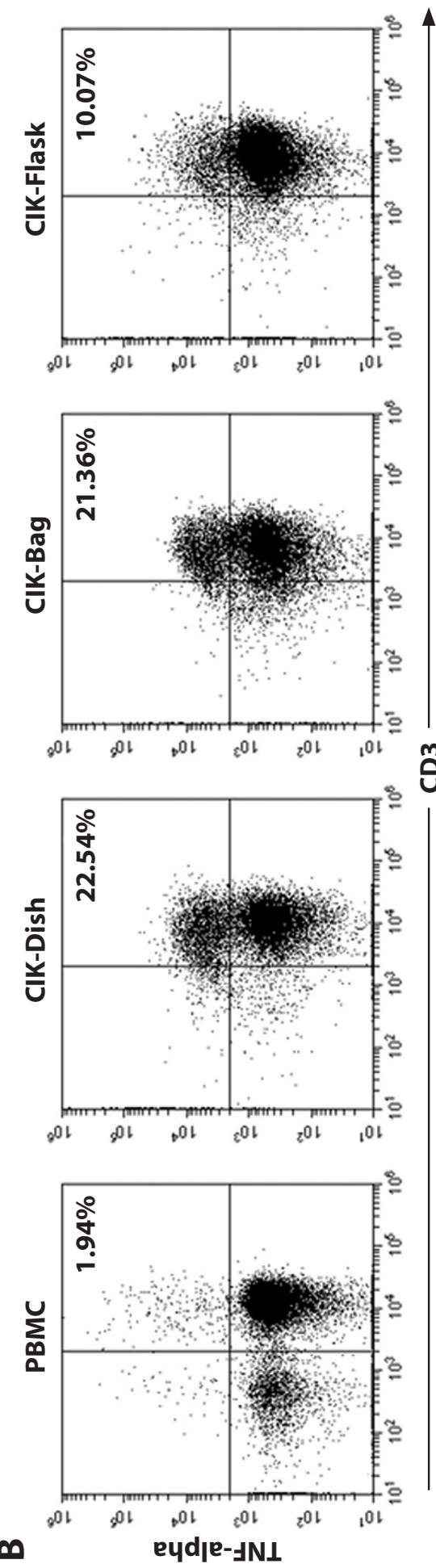

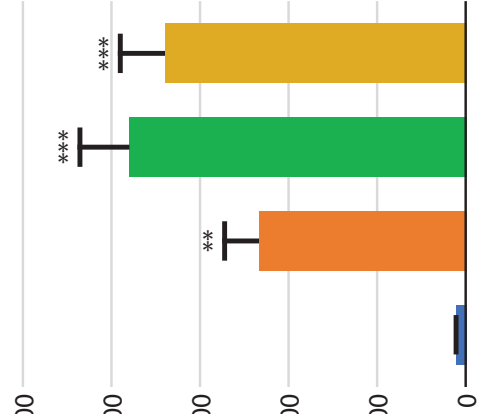

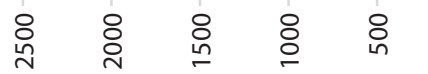
(و0l) גәqunu s||ә弓+ g zue
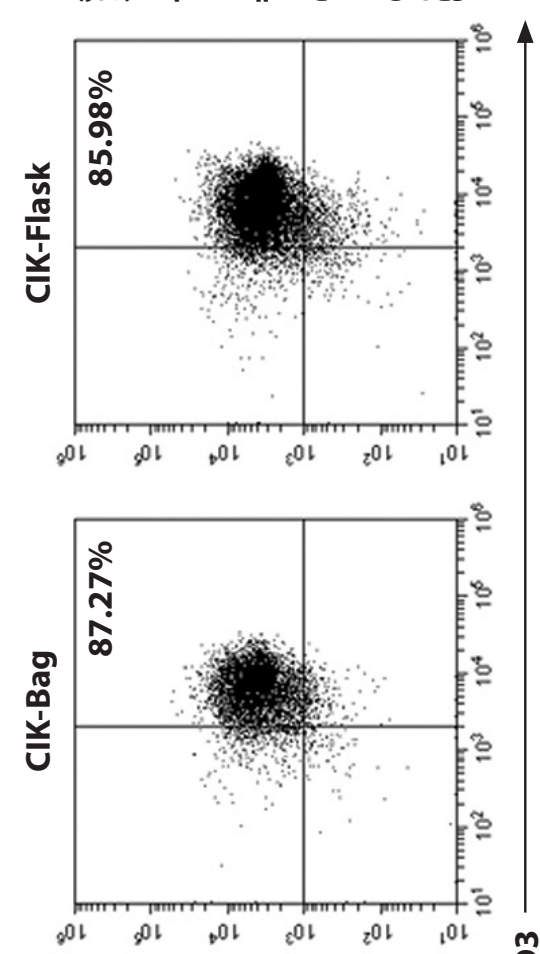

ڤิ
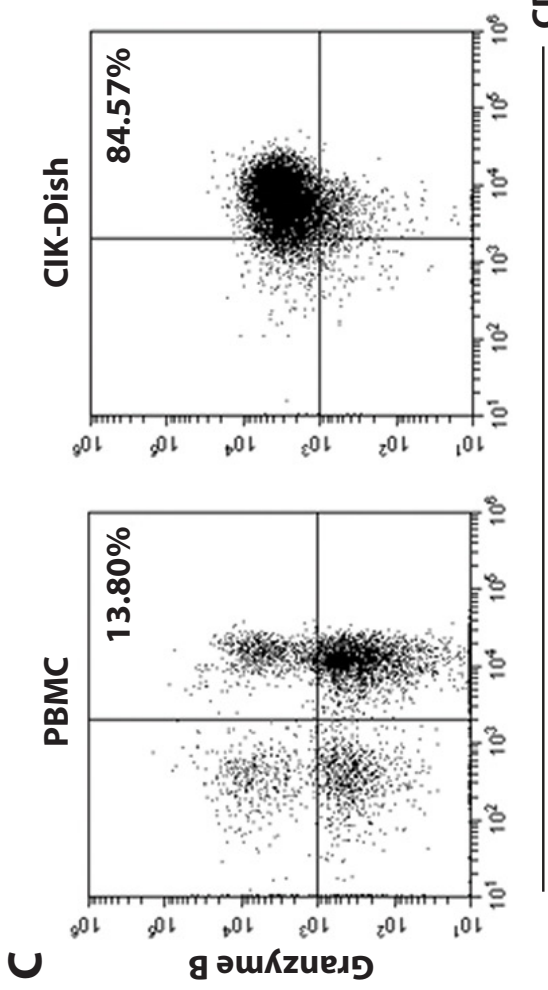

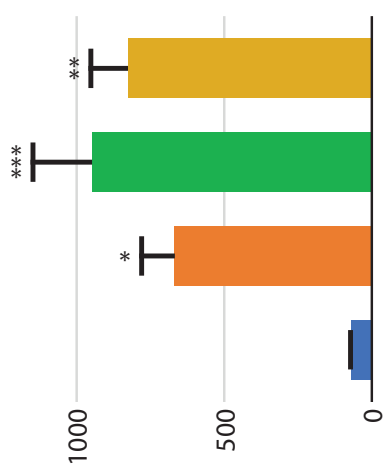

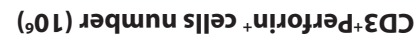
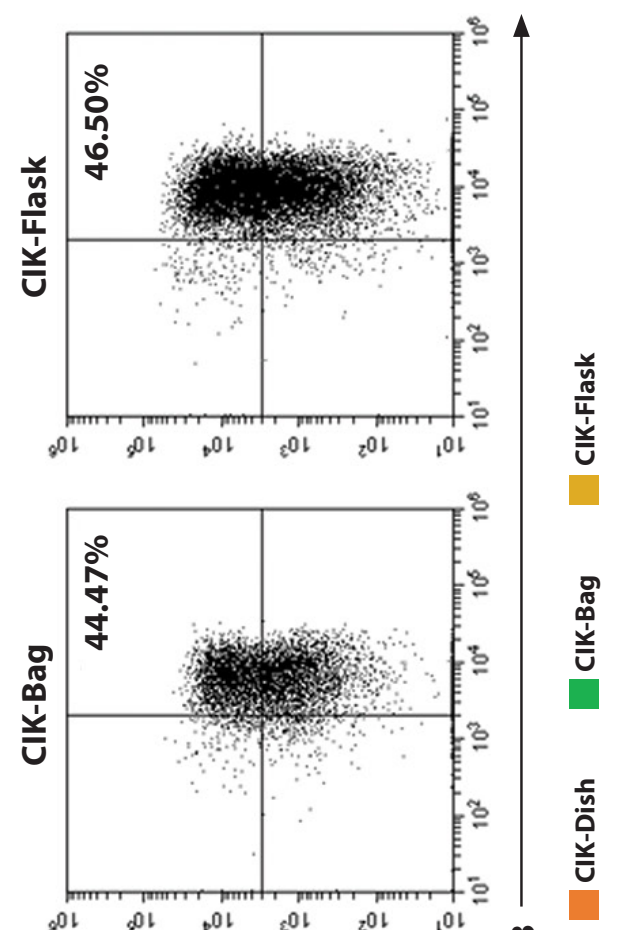

@̊
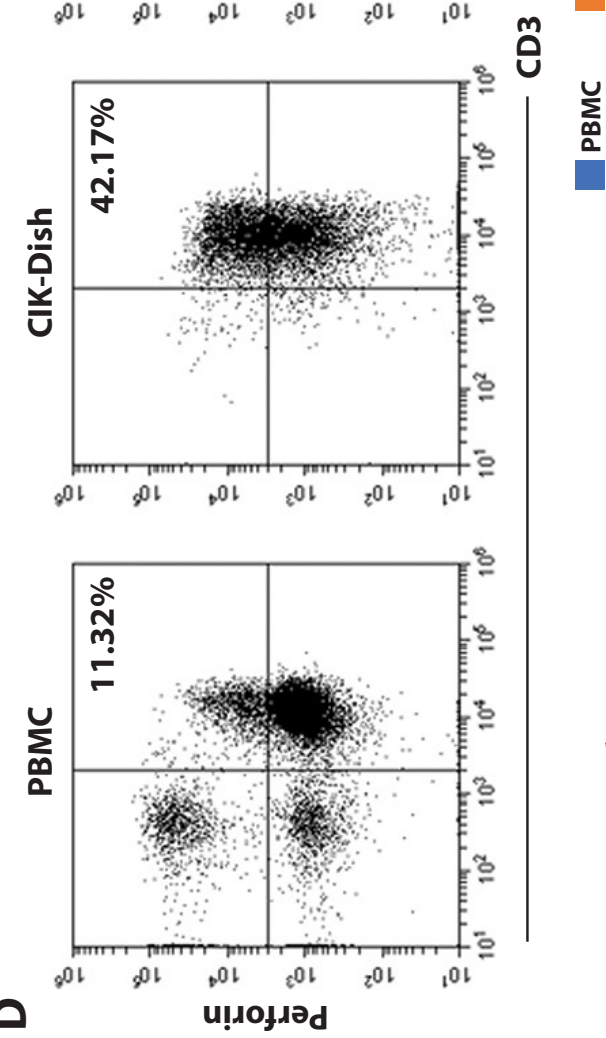


\section{Discussion}

CIK cells are currently applied in a number of clinical trials, so it is crucial to develop a cost-effective CIK cell- culture protocol to achieve successful cancer immunotherapy. Selection of cell culture plasticwares is one of most important factors affecting the quality and quantity of cultured cells. We compared three major types of cell culture plasticwares: a petridish, static bag, and gas-permeable flask, in culturing CIK cells, with a focus on their safety and efficiency. As both a cell-culture bag and flask are closed systems, the chance of contamination with these is undoubtedly lower than with a petridish, which is an open system. The total CIK cell numbers in a cell-culture bag and flask were significantly higher than in the petridish. This suggests that a cell-culture bag and flask provide a better vicinity for CIK cell proliferation than does a petridish. Additionally, CIK cells cultured in all three containers express major surface-marker proteins and cytokines equally. All in all, both the cell-culture bag and flask seemed to be more suitable for culturing CIK cells, considering their safety and efficiency. Finally, in clinical practice, cost-effectiveness is a very important factor. A cell-culture bag is generally cheaper than a flask. Therefore, taking all these factors into consideration, we propose that a cell-culture bag is the most desirable cell-culture plasticware to culture CIK cells for clinical application.

\section{Competing interests}

The authors declare that they have no competing interest.

\section{Author's contributions}

PP performed experiments, data analysis, and manuscript writing. $\mathrm{CP}$ performed experiments. KS designed and conducted experiments, and manuscript writing. All authors have read and approved the final manuscript.

\section{Acknowledgements}

The authors wish to thank Dr. Suradej Hongeng, Dr. Adisak Wongkajornsilp, and

Dr. Usanarat Anurathapan for helpful advice. This work was supported by National Science and Technology Development Agency (FDA-CO-2559-3325TH) and the Siriraj Foundation (D-003658).

\section{References}

1. Schmidt-Wolf IG, Negrin RS, Kiem HP, Blume KG, Weissman IL. Use of a SCID mouse/human lymphoma model to evaluate cytokine-induced killer cells with potent antitumor cell activity. J Exp Med. 1991;174(1): 139-49.

2. Linn YC, Hui KM. Cytokine-induced killer cells: NK-like T cells with cytotolytic specificity against leukemia. Leuk Lymphoma. 2003;44(9): 1457-62.

3. Alvarnas JC, Linn YC, Hope EG, Negrin RS. Expansion of cytotoxic CD3+ CD56+ cells from peripheral blood progenitor cells of patients undergoing autologous hematopoietic cell transplantation. Biol Blood Marrow Transplant. 2001;7(4):216-22.

4. Marten A, Greten T, Ziske C, Renoth S, Schottker B, Buttgereit P, et al Generation of activated and antigen-specific T cells with cytotoxic activity after co-culture with dendritic cells. Cancer Immunol Immunother. 2002;51(1):25-32.

5. Timalsena S, Pluangnooch P, Wongkajornsilp A, Soontrapa K. An additional CD28 costimulatory signal enhances proliferation and cytotoxicity of murine T cell-derived CIK cell. Asian Pac J Allergy Immunol. 2017;35(2):67-74.

6. Leemhuis T, Wells S, Scheffold C, Edinger M, Negrin RS. A phase I trial of autologous cytokine-induced killer cells for the treatment of relapsed Hodgkin disease and non-Hodgkin lymphoma. Biol Blood Marrow Transplant. 2005;11(3):181-7.

7. Schmeel FC, Schmeel LC, Gast SM, Schmidt-Wolf IG. Adoptive immunotherapy strategies with cytokine-induced killer (CIK) cells in the treatment of hematological malignancies. Int J Mol Sci. 2014;15(8): 14632-48.

8. Niu Q, Wang W, Li Y, Qin S, Wang Y, Wan G, et al. Cord blood-derived cytokine-induced killer cells biotherapy combined with second-line chemotherapy in the treatment of advanced solid malignancies. Int Immunopharmacol. 2011;11(4):449-56.

9. Pluangnooch P, Timalsena S, Wongkajornsilp A, Soontrapa K. Cytokine -induced killer cells: A novel treatment for allergic airway inflammation. PLoS One. 2017;12(10):e0186971. 